\title{
Transplantated Mesenchymal Stem Cells Derived from Embryonic Stem Cells Promote Muscle Regeneration and Accelerate Functional Recovery of Injured Skeletal Muscle
}

\author{
Nana Takenaka Ninagawa, ${ }^{1, *}$ Eri Isobe, ${ }^{2}$ Yuri Hirayama, ${ }^{2}$ Rumi Murakami, ${ }^{2}$ Kazumi Komatsu, ${ }^{2}$ \\ Masataka Nagai, ${ }^{2}$ Mami Kobayashi, ${ }^{1}$ Yuka Kawabata, ${ }^{2}$ and Shigeko Torihashi ${ }^{1,2}$
}

\begin{abstract}
We previously established that mesenchymal stem cells originating from mouse embryonic stem (ES) cells (E-MSCs) showed markedly higher potential for differentiation into skeletal muscles in vitro than common mesenchymal stem cells (MSCs). Further, the E-MSCs exhibited a low risk for teratoma formation. Here we evaluate the potential of E-MSCs for differentiation into skeletal muscles in vivo and reveal the regeneration and functional recovery of injured muscle by transplantation. E-MSCs were transplanted into the tibialis anterior (TA) muscle $24 \mathrm{~h}$ following direct clamping. After transplantation, the myogenic differentiation of E-MSCs, TA muscle regeneration, and re-innervation were morphologically analyzed. In addition, footprints and gaits of each leg under spontaneous walking were measured by CatWalk XT, and motor functions of injured TA muscles were precisely analyzed. Results indicate that $>60 \%$ of transplanted E-MSCs differentiated into skeletal muscles. The crosssectional area of the injured TA muscles of E-MSC-transplanted animals increased earlier than that of control animals. E-MSCs also promotes re-innervation of the peripheral nerves of injured muscles. Concerning function of the TA muscles, we reveal that transplantation of E-MSCs promotes the recovery of muscles. This is the first report to demonstrate by analysis of spontaneous walking that transplanted cells can accelerate the functional recovery of injured muscles. Taken together, the results show that E-MSCs have a high potential for differentiation into skeletal muscles in vivo as well as in vitro. The transplantation of E-MSCs facilitated the functional recovery of injured muscles. Therefore, E-MSCs are an efficient cell source in transplantation.
\end{abstract}

Key words: CD105; embryonic stem cells; functional recovery; MSC; regeneration of skeletal muscle

\section{Introduction}

$\mathbf{M}$ ATURE SKELETAL MUSCLE CELLS are one of the cell types generally lacking regenerative capacity. When they are injured or damaged by disease, their regeneration from undifferentiated cells or progenitors provides an important clinical application, that is, cell therapy and interesting issues from the scientific viewpoint. Cell transplantation approaches for degenerative muscle injury and disease aim at repairing muscle damage by their delivery of cells that can differentiate into skeletal muscle. A variety of cell sources have been proposed, and each has its own advantages and disadvantages.

Satellite cells are one of the sources of cell therapy for regenerating injured skeletal muscles because of their intrin- sic myogenic potential. However, in several myopathies, including Duchenne muscular dystrophy, continuous muscle degeneration-regeneration cycles lead to a depletion of the satellite cell pool. They expand poorly in vitro and also rapidly undergo senescence. ${ }^{1}$ Alternative sources are represented by embryonic stem (ES) cells. They exhibit significant potential to differentiate into every cell type, including skeletal muscle cells, and can expand with no change in their characteristics. To advance cell therapies, it is necessary to determine how to control the differentiation of ES cells to a specific cell type in the face of their ability to generate a teratoma. ${ }^{2}$ However, very few experiments have succeeded in the in vivo transplantation of ES cells or induced pluripotent stem cells (iPS cells) for skeletal muscle regeneration. ${ }^{3-7}$ Several

\footnotetext{
${ }^{1}$ Department of Rehabilitation Sciences, Graduate School of Medicine; ${ }^{2}$ Department of Physical Therapy, School of Health Sciences; Nagoya University, Nagoya, Japan.

*Current address: Department of Clinical Application, Center of iPS Cell Research and Application, Kyoto, Japan.
} 
reports have demonstrated that mesenchymal stem cells (MSCs) have the potential to differentiate into any mesenchymal cell type, such as osteocytes, chondrocytes, and adipocytes. 8,9 However, it is well known that MSCs obtained from bone marrow are quite limited in population; their isolation is invasive and involves a risk. Recently, adipose tissue was found to be a useful and rich source of MSCs. Although MSCs from adipose tissue have therapeutic efficiency, their isolation and purification from adult tissues still require complicated and troublesome procedures. Because the definition of MSCs remains unclear, the MSCs from adipose tissue are used in many studies involving cell mixtures. ${ }^{8}$ Furthermore, they readily differentiate into adipocytes, osteocytes, and chondrocytes but not into skeletal muscle cells. Only a few reports show them to generate muscle cells. ${ }^{9-12}$

Mouse ES cells, on the other hand, are pluripotent, and their induction of adipogenesis has been well described. Currently, we established a novel method for the induction and collection of MSCs using a typical cell surface marker, CD105, via adipogenesis from mouse ES cells without genetic manipulation. Moreover, we found that MSCs derived from ES cells (E-MSCs) have a high potential for differentiation into skeletal muscles and for expansion in vitro. E-MSCs have never generated teratoma, even after $>6$ months in vivo. ${ }^{13}$ Thus, in the present study, the aim was to clarify the potential of E-MSCs for the promotion of morphological and functional recovery in the injured muscles of mice into which E-MSCs are transplanted. To start, mouse ES cells were induced to adipogenic cells, and E-MSCs were sorted by CD105 during the induction of adipogenesis and just before the appearance of adipocytes. Collected E-MSCs were then transplanted into injured tibialis anterior (TA) muscles $24 \mathrm{~h}$ after clamping. The myogenic differentiation of E-MSCs and the regeneration of injured TA muscles were investigated. MSCs from iPS cells were also used under the same conditions. The physical functions of muscles were evaluated using a functional analyzer CatWalk XT (Noldus Information Technology, Wageningen, The Netherlands) after transplantation.

We demonstrate that both E-MSCs and MSCs from iPS cells maintain a high potential for differentiation into skeletal muscles without the formation of a teratoma in vivo after transplantation into impaired muscles. In addition, E-MSCs promote the recovery of injured muscle cells and the reinnervation of the peripheral nerves, probably through the secretion of cytokines. As a result, the transplantation of E-MSCs accelerates the functional recovery of physically injured muscles.

\section{Materials and Methods}

\section{Mouse ES cells and iPS cells}

G4-2 mouse ES cells (carrying the enhanced green fluorescent protein $[E g f p]$ gene under the control of a cytomegalovirus/chicken $\beta$-actin promoter, a kind gift from Dr. H. Niwa) and CCE/n LacZ ES cells (expressing the LacZ gene, a kind gift from Dr. H. Sakurai) ${ }^{4}$ were expanded in a culture medium, ES-DMEM, comprised of Dulbecco's modified Eagle's medium (Sigma, St. Louis, MO) with $0.1 \mathrm{mM}$ of nonessential amino acids (Gibco, Carlsbad, CA), $100 \mathrm{mM}$ of sodium pyruvate (Gibco), $100 \mathrm{mM}$ of 2-mercaptoethanol (Sigma), and 0.5\% of an antibiotic-antimycotic (Gibco) containing 10\% fetal bovine serum (FBS; Biological Industries, Kibbuiz, Israel). For the expansion of M-ESCs, $1000 \mathrm{U} / \mathrm{mL}$ of a leukemia inhibitory factor (LIF; Chemicon, Temecula, CA) was added in ES-DMEM.

Mouse iPS cells ${ }^{14}$ and DsRed ES cells (expressing the DsRed gene, a kind gift from Dr. Sasaki and Mr. S. Yoshie) were maintained on SNL feeder cell layers that were mitotically inactivated with $10 \mu \mathrm{g} / \mathrm{mL}$ mitomycin C (Kyowa Hakkou Kirin, Tokyo, Japan). SNL feeder cells are STO feeder cells transformed with neomycin resistance and LIF genes.

\section{Animals, injured model, and transplantation}

For the transplantation of MSCs, 8-week-old immunodeficient mice (SCID) were purchased from Charles River Japan (Yokohama, Japan) and used following the guidelines of the Nagoya University Graduate School of Medicine for the care and use of animals. Mice $(n=55)$ were anesthetized for surgery with subcutaneous injections of sodium pentobarbital $(80 \mathrm{mg} / \mathrm{kg})$. The midportion of the TA muscle was then continuously crushed by direct clamping with a forceps for $1 \mathrm{~min}$ under the same pressure gauge as a constant pressure. E-MSCs, $1 \times 10^{5}$ of CD105 ${ }^{+}$cells suspended in phosphatebuffered saline (PBS; $20 \mu \mathrm{L}$ ) were injected at the center of the injured sites of the TA muscles at $24 \mathrm{~h}, 3$ days, and 1 week after injury, respectively.

\section{Generation, sorting, and passage of E-MSCs or MSCs derived from iPS cells, and generation of MSCs from adipose tissue}

The experimental protocol is shown in Figure 1. For the induction of adipogenesis, mouse ES cells and iPS cells were incubated for 2 days without LIF and compacted to form embryoid bodies (EBs) in hanging drops. On the following 2 days, they were exposed to $10^{-7} \mathrm{M}$ all-trans retinoic acid (RA, Sigma) in culture medium followed by washing for 2 days without RA. After day 6, EBs were plated onto gelatin-coated dishes and then incubated with $1.7 \mu \mathrm{M}$ insulin (Sigma) and $0.3 \mu \mathrm{M}$ 3,3,5-triiodo-L-thyronine (Sigma) in ESDMEM. Developing EBs were detached from the dishes, isolated with $5 \mathrm{mM}$ EDTA in PBS (pH 7.4), and then sorted by a magnetic cell separation system (MACS; Miltenyi Biotec, Auburn, CA) using both an anti-CD105 antibody (R\&D Systems, Minneapolis, MN) and an antirat antibody conjugated with magnetic beads (Miltenyi Biotec). The sample preparation, magnetic labeling, and magnetic separation with miniMS columns were conducted according to the manufacturer's instructions. After MACS separation, $\mathrm{CD} 105^{+}$cells were transferred for culture to coating dishes. CD105 ${ }^{+}$cells were expanded using STK2 medium (DS Pharma Biomedical, Osaka, Japan). Just before transplantation, a small number of undifferentiated cells that form cell aggregation colonies were depleted by laser irradiation using laser microdissection LMD7000 (Leica Microsystems, Tokyo, Japan). MSCs generated from adipose tissue (ADSCs) were isolated from adipose tissues surrounding testes. The protocol mainly followed that of an earlier report. ${ }^{13}$ Fat tissues were dissected and incubated with an enzyme solution containing $1 \mathrm{mg} / \mathrm{mL}$ type 1 collagenase (Wako Pure Chemical Industries, Osaka, Japan), $1 \%$ bovine serum albumin (Sigma) and $10 \%$ penicillin and streptomycin (Wako) in PBS for $60 \mathrm{~min}$ at $37^{\circ} \mathrm{C}$. Cells released from adipose tissues were filtered through a cell strainer with $100-\mu \mathrm{m}$ meshes (Falcon) and collected by centrifugation at 


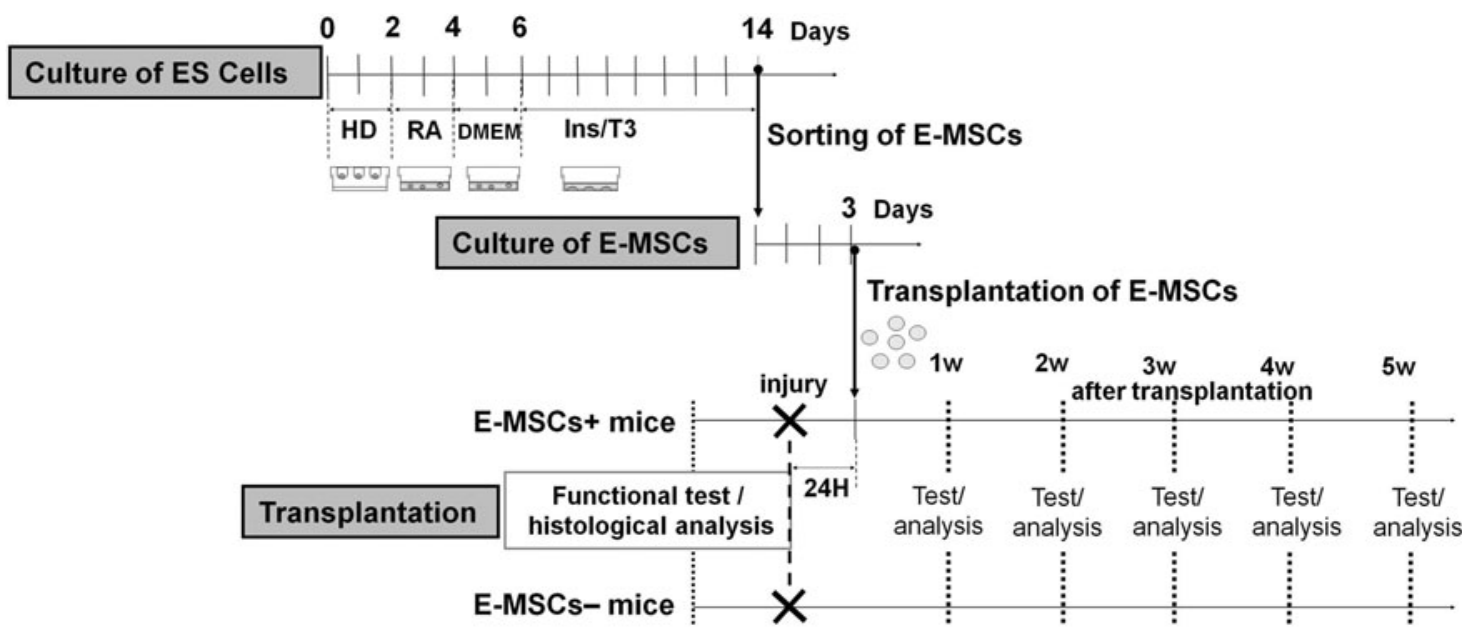

FIG. 1. Scheme of experimental processes and time schedule using E-MSCs. The experiment was composed of three main processes. The first process was induction of E-MSCs and their sorting. The second was expansion of the population of EMSCs. The final process was the transplantation of E-MSCs and the analysis of the effects. When CD105 ${ }^{+}$cells increased and reached the maximum population (day 14), they were isolated and sorted by MACS separation system and termed EMSCs. After that, they were cultured in MSC culture medium for 3 days. Finally, E-MSCs $\left(1 \times 10^{5}\right.$ cells $)$ were transplanted into injured TA muscles, $24 \mathrm{~h}$ after crushing. E-MSCs, mesenchymal stem cells originating from mouse embryonic stem cells; TA, tibialis anterior; ES, embryonic stem (cell); HD, hanging drop; RA, retinoic acid treatment; DMEM, Dulbecco's modified Eagle's medium (normal ES culture medium); Ins/T3, adipogenic medium; T3, triiodothyronine.

$300 \mathrm{~g}$ for $10 \mathrm{~min}$. The pellet was resuspended in STK1 (DS Pharma Biomedical), a medium for a primary culture of mesenchymal stem cells.

\section{Histological analysis}

After 1, 2, 3, or 4 weeks of actual transplantation or sham operation (crush injuries only), mice were sacrificed and fixed with $4 \%$ paraformaldehyde, and their muscles were frozen. Muscle cryosections (10 $\mu$ m thick) were cut from the midportion of TA muscles (the injured region) using a cryostat. Sections were stained with hematoxylin and eosin (H-E) for the examination of fiber cross-sectional areas and central nuclei (a marker of the regenerating muscle fibers). For detection of $\beta$-galactosidase activity, sections of transplanted tissue were incubated in $3.1 \mathrm{mM}$ potassium ferricyanide (Wako), $3.1 \mathrm{mM}$ potassium ferrocyanide (Wako), and $1 \mathrm{mM} \mathrm{MgCl}_{2}$ (Sigma) in PBS with $0.4 \mathrm{mg} / \mathrm{mL}$ X-gal (Wako) overnight at $37^{\circ} \mathrm{C}$. The stained section was washed twice in PBS. After that some sections were stained with eosin.

Sections were imaged using a BZ-9000 microscope (Keyence, Osaka, Japan) and were recorded and analyzed with a BZ-II analysis application (Keyence).

\section{Immunohistochemistry}

For detection of EGFP, the sections were blocked by $0.3 \%$ hydrogen peroxide-containing methanol and diluted normal blocking serum. Samples were incubated with the first antibodies followed by biotinylated secondary antibodies. Sections were then incubated with Vectastain ${ }^{\circledR}$ Elite $A B C$ Reagent (Vector Laboratories, Burlingame, CA). Finally, EGFP was detected in peroxidase substrate solution $(0.05 \%$ 3,3'-diaminobenzidine [DAB] and $0.015 \% \mathrm{H}_{2} \mathrm{O}_{2} ;$ Sigma) until the desired stain intensity developed. After that, sections were stained with hematoxylin. Serial sections were stained with H-E. EGFP-positive cells were considered to be myogenic if the serial section was stained with eosin.

\section{Fluorescent immunostaining}

Tissues were fixed with $4 \%$ paraformaldehyde in PBS for $3 \mathrm{~h}$. Cryosections of tissues were processed for fluorescent immunostaining. Samples were incubated with the first antibodies followed by Alexa Fluor-labeled secondary antibodies as shown in Table 1. For detection of motor end plates, Alexa Fluor 594-conjugated $\alpha$-bungarotoxin ( $\alpha$ BT, 1:200; Molecular Probes, Leiden, The Netherlands) was applied and incubated for $30 \mathrm{~min}$ at room temperature. Some samples were counterstained with 4',6-diamidino-2phenylindole (1:1000; KPL, Gaithersburg, MD) just before mounting with Fluoromount ${ }^{\mathrm{TM}}$ (DBS, Pleasanton, CA). Samples were observed using the BZ-9000 fluorescent microscope and were recorded with a BZ-II analysis application. When the first antibodies were omitted, no specific immunostaining was observed.

\section{Image acquisition, cell quantification, and statistics}

Digital images of 10 random fields in each sample were taken with the BZ-9000 microscope, and labeled cells were counted under $10 \times$ or $20 \times$ objective lenses. Microsoft Excel (Redmond, WA) was used for tabulation and statistical analysis.

\section{Gait analysis}

To follow the functional recovery of an injured mouse, we performed gait analysis using CatWalk (Noldus). We measured the walking locomotor activities of mice given crush injuries and transplantation, sham operations (crush injuries only), or control animals with neither injuries nor transplantations ( $n=20 /$ condition). 
Table 1. Primary Antibodies Used for Immunohistochemistry

\begin{tabular}{lllr}
\hline Antigen & \multicolumn{1}{c}{ Antibody } & \multicolumn{1}{c}{ Species } & Dilution \\
\hline CD105 & 243-B3 (R\&D Systems, Inc.) & Rat polyclonal & $100 \times$ \\
MHC & A4.1025 (Upstate) & Mouse monoclonal & $200 \times$ \\
M-cadherin & 12G4 (Invitrogen) & Mouse monoclonal & $20 \times$ \\
Pax7 & (GeneTex) & Mouse monoclonal & $50 \times$ \\
SMI-31 & SMI31-R (Covance) & Mouse monoclonal & $1000 \times$ \\
EDFP/GFP & (Novus Biologicals, Inc.) & Rabbit polyclonal & $100 \times$ \\
MOMA-2 & AbD (Serotec) & Rat monoclonal & $50 \times$ \\
\hline
\end{tabular}

The secondary antibody was Alexa Fluor 594 goat antirat IgG (1:400), Alexa Fluor 594 goat anti-mouse IgG (1:400), Alexa Fluor 488 goat antimouse IgG (1:400), Alexa Fluor 594 goat anti-rabbit IgG (1:400), or Alexa Fluor 488 anti-rabbit IgG (1:400). All Alexa Fluor-labeled secondary antibodies were from Molecular Probes (Leiden, The Netherlands).

MHC, myosin heavy chain.

Mice were analyzed at 1-week intervals; specifically, 1 week prior to surgery (crush injuries), on postoperative day 1 , and at postoperative weeks $1,2,3,4$, and 5 .

We used the value of a percentile of the load response phase, and the maximum contact area $\left(\mu \mathrm{m}^{2}\right)$ as the evaluation index of functional recovery of the injured TA muscles.

\section{Statistical analysis}

The experimental values are presented as means \pm SD. Statistical analysis was performed in all experiments by Excel and SPSS v. 16.0 (SPSS Inc., Chicago, IL) software for measurements, and comparisons between groups were assessed by Student's $t$-test and Mann-Whitney $U$ test. Adjustment for multiple comparisons was done, when necessary, by the use of the Bonferroni correction method; values of $p \leq 0.05$ were considered statistically significant.

\section{Results}

Time course of skeletal muscle damage and regeneration after crush injury

The manner of injury proved to be a simple, stable, reliable, and reproducible method: clamping for $1 \mathrm{~min}$ using forceps under the same pressure gauge. At the center of the crush area (approximately $3.5 \mathrm{~mm}$ in diameter and $5 \mathrm{~mm}$ of length in the TA muscle), entire cross sections were occupied by damaged fibers $24 \mathrm{~h}$ after injury. Damage to the muscle resulted in severe inflammation $24-48 \mathrm{~h}$ after injuries with accumulation of MOMA2 expressing macrophages (Fig. 2A-a, $b, e, f)$. Though injured muscle fibers were entirely destroyed, many of their shapes on cross sections were still recognizable. After a week, muscle fibers in the injured area showed signs of regeneration that involved small muscle fibers with nuclei located at the central portion of fibers in the cross section (Fig. $2 \mathrm{~A}-\mathrm{c}, \mathrm{g})$. Five weeks later, muscle fibers in the injured area had regenerated completely.

E-MSCs were transplanted into injured muscles $24 \mathrm{~h}, 3$ days, and 1 week after injury to determine the suitable timing for transplantation. One week after transplantation, samples were quantified for the percentage of $\mathrm{EGFP}^{+}$and myosin heavy chain (MHC) positive muscle fibers (E-MSCs among regenerating muscle cells). E-MSCs transplanted $24 \mathrm{~h}$ and 3 days after injury showed higher potential of myogenic differentiation compared to those transplanted 1 week after injuries as reported previously. ${ }^{3,10,15} \mathrm{EGFP}^{+} / \mathrm{MHC}^{+}$ cells became approximately 2 or 8 times fewer than those of
$24 \mathrm{~h}$ after injury, respectively (Fig. 2B,C). Therefore, we carried out the transplantation of E-MSCs $24 \mathrm{~h}$ after the injury when the muscle fibers sustained damage until the start of regeneration.

\section{Myogenesis of E-MSCs in vivo}

E-MSCs were transplanted into injured TA muscles $24 \mathrm{~h}$ after clamping. Transplanted cells located in the injected area did not move to other regions during the following 1-3 weeks, remaining within $5 \mathrm{~mm}$ of the injected sites. In other organs examined, such as lung, kidney, and spleen, we did not find EGFP-expressing cells $\left(\mathrm{EGFP}^{+}\right.$cells; data not shown). They were clearly distinguishable from host cells by their EGFP immunoreactivity. A marker of the muscle satellite cell, Pax7, was expressed in the nucleus attached to $\mathrm{EGFP}^{+}$cells derived from ES cells (Fig. 3A-a). Although small cytoplasms of Pax7-immunopositive cells (Pax7 ${ }^{+}$ cells) were never identified clearly, Pax7 immunoreactivities were located at the nuclei and showed a proximity to myofibers expressing EGFP. Moreover, $\mathrm{EGFP}^{+}$cells grew larger, with some of them expressing $\mathrm{M}$-cadherin immunoreactivity (Fig. 3A-b). $\mathrm{EGFP}^{+}$cells occasionally appeared as multinuclear cells in the cross section. MHC was expressed in those multinuclear $\mathrm{EGFP}^{+}$cells indicating muscle fibers (Fig. 3Ac). Two weeks following transplantation, $\mathrm{MHC}^{+}$cells among $\mathrm{EGFP}^{+}$cells increased, becoming large enough to involve several nuclei of the outermost cells in the cross section. The myogenesis among transplanted E-MSCs was confirmed by horseradish peroxidase (HRP) staining (Fig. 3A-d). One week and 2 weeks after transplantation, we quantified the ratio of $\mathrm{MHC}^{+}$cells among EGFP ${ }^{+}$cells (myogenic E-MSCs among transplanted E-MSCs). One week after transplantation, $50 \%$ of transplanted E-MSCs $\left(\mathrm{EGFP}^{+}\right.$cells) differentiated into $\mathrm{MHC}^{+}$skeletal muscles. After 2 weeks, $\sim 80 \%$ of $\mathrm{EGFP}^{+}$cells became $\mathrm{MHC}^{+}$muscle fibers (Fig. 3B). The number of myogenic cells among $\mathrm{EGFP}^{+}$cells was also analyzed after 1 and 2 weeks by HRP enzyme histochemistry using $\mathrm{DAB}$ and intensive eosin staining in their serial sections. Although it was a smaller population than EGFP and MHC double-positive cells, the myogenic cells calculated by immunohistochemistry were $>60 \%$ transplanted E-MSCs after 2 weeks (Fig. 3B). When we transplanted E-MSCs from $\mathrm{Lac}-\mathrm{Z}$ ES cells, they also differentiated into skeletal muscles with high efficiency in vivo. One week after transplantation, several muscle fibers with Lac-Z-positive nuclei were observed in regenerating areas, but not in intact areas (Fig. 3C). Other 

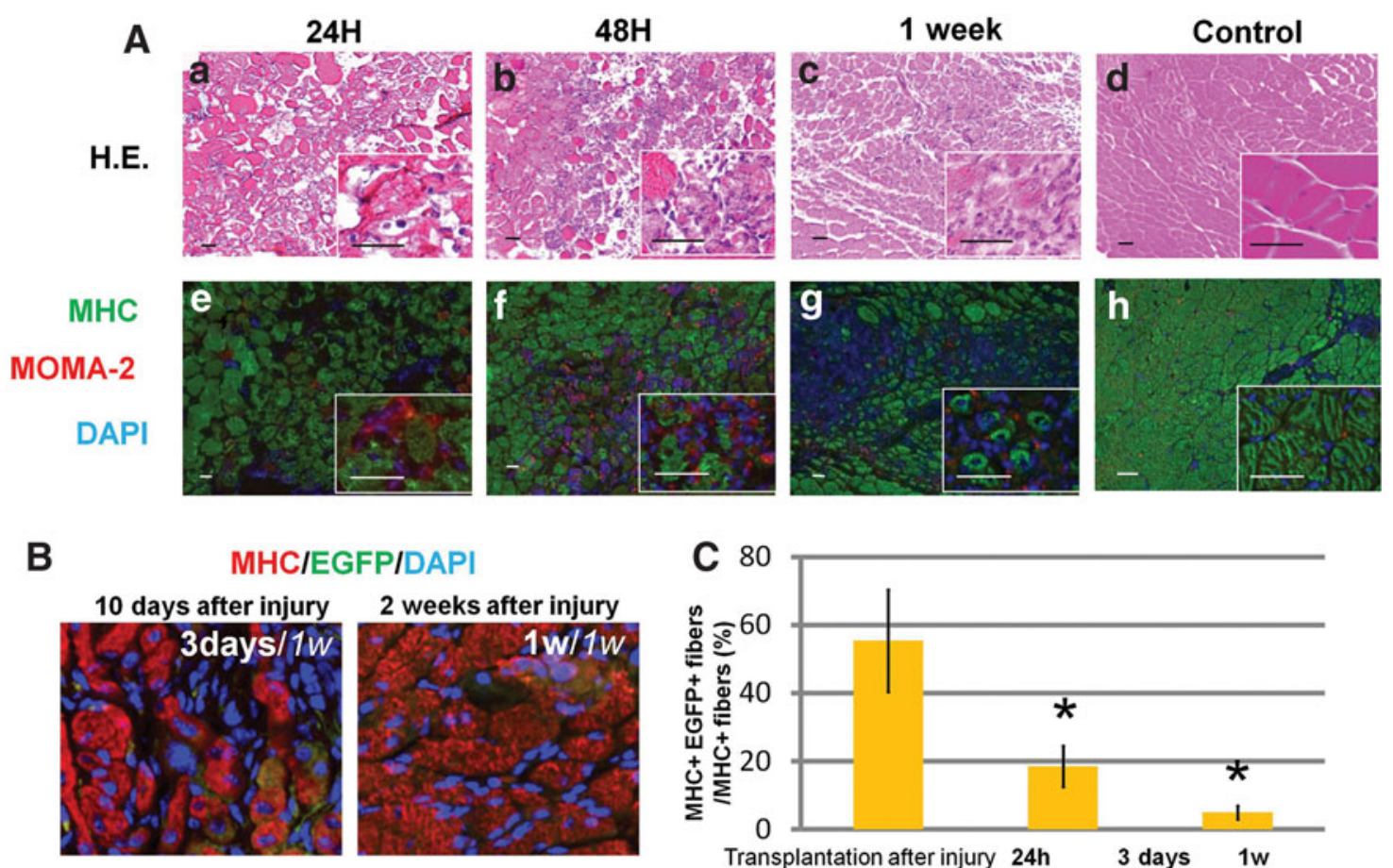

B

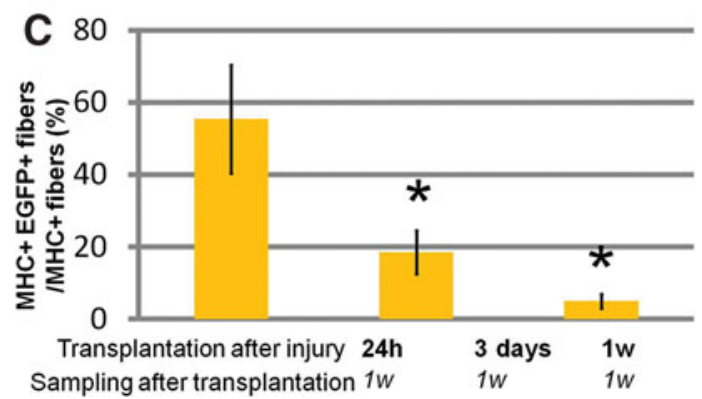

FIG. 2. Crush injury models. (A) Alteration of skeletal muscles after crush injury. At $24 \mathrm{~h}$ after crush injury, muscle fibers were significantly impaired, but their contours in cross sections were still recognizable (a, e). After $48 \mathrm{~h}$, many macrophages (red) had infiltrated injured muscle tissues dynamically $(\mathbf{b}, \mathbf{f})$. After 1 week, injured muscle fibers almost degenerated, and a small number of regenerating muscle fibers with nuclei at the center of each fiber appeared (c, g). Control (noninjured) muscle fibers are shown for comparison $(\mathbf{d}, \mathbf{h})$. (a-d) Hematoxylin and eosin $(\mathrm{H}-\mathrm{E})$ staining; (e-h) fluorescent immunostaining. MHC (green), MOMA-2 (red), 4',6-diamidino-2-phenylindole (DAPI; blue). Insets: Higher magnifications of each image. Scale bars = $50 \mu \mathrm{m}$. (B) Cross sections of SCID mice 1 week after the transplantation. Some $\mathrm{MHC}^{+}$cells (red), a marker of mature skeletal muscle fiber, were colocalized with enhanced green fluorescent protein-positive (EGFP ${ }^{+}$) cells (green) derived from E-MSCs. E-MSCs were transplanted 3 days (10 days after injury; left image) and 1 week ( 2 weeks after injury; right image) after the crush injury. (C) The sum of all $\mathrm{MHC}^{+}$muscle fibers in the transplanted area was taken as $100 \%$, and the percentages of EGFP and MHC double-positive muscle fibers were calculated. A high ratio of myogenesis from E-MSCs transplanted $24 \mathrm{~h}$ post-injury is shown. With transplantation 1 week after crush injury, EGFP and MHC double-positive skeletal muscles decreased significantly. Twenty random visual fields in each group were measured; $\left({ }^{*} p<0.05\right)$.

pluripotent stem cell population such as Ds-Red ES cells and iPS cells showed similar high potential for differentiation into skeletal muscle cells to our E-MSCs in vitro (Fig. 3D). However, only a few ADSCs differentiated into muscle cells under the same conditions (Fig. 3E).

\section{Transplanted E-MSCs promote recovery of injured skeletal muscles}

After 2 weeks, injured muscle fibers had entirely decomposed, and the regeneration of myofibers had already begun. The average cross-sectional areas of myofibers indicated the thickness of restored myofibers. The average cross-sectional areas of E-MSC ${ }^{-}$mice (without transplantation) were about 7 times smaller than the control (noninjured fibers). On the other hand, though the muscle fibers in E-MSC $^{+}$mice (with transplantation) showed a significantly higher cross-sectional area of myofibers compared to E-MSC $^{-}$mice, it was still 2 times smaller than the control (Fig. 4A, B). Three weeks after transplantation, almost all muscle fibers in the E-MSC ${ }^{+}$mice subsequently presented normal muscle features. The histograms showed that the percentage of large muscle fibers had increased. Although the muscle fibers in $\mathrm{E}-\mathrm{MSC}^{-}$mice had gradually increased the cross-sectional area of the muscle fiber after 3 weeks, they had not recovered completely even 4 weeks after injury (Fig. 4C).

\section{E-MSCs accelerated re-innervation of regenerating muscle fibers}

After the injury, the re-innervation indicated by the number of nerve muscular junctions (NMJs) and nerve fiber bundles was measured in a cross section stained with $\alpha$-BT or SMI-31. One week after injury, almost all SMI- $31^{+}$bundles and $\alpha-\mathrm{BT}^{+}$NMJs were broken and had disappeared from the injured areas in cross sections (Fig. 5A). In E-MSC ${ }^{+}$ mice, NMJs decreased 1 week after the injury, and then increased significantly to recover after 3 weeks. However, in E-MSC $^{-}$mice, the number of NMJs after 3 weeks still remained lower than the control (noninjured muscle; Fig. 5B). Transplanted E-MSCs promoted the regeneration of peripheral nerves that had once been degenerated by crush injury (Fig. 5C). 
A Pax7/DAPI/EGFP

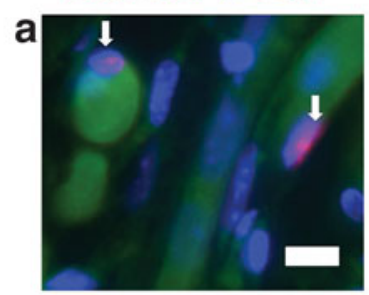

c

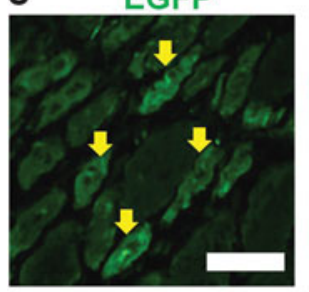

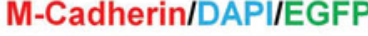
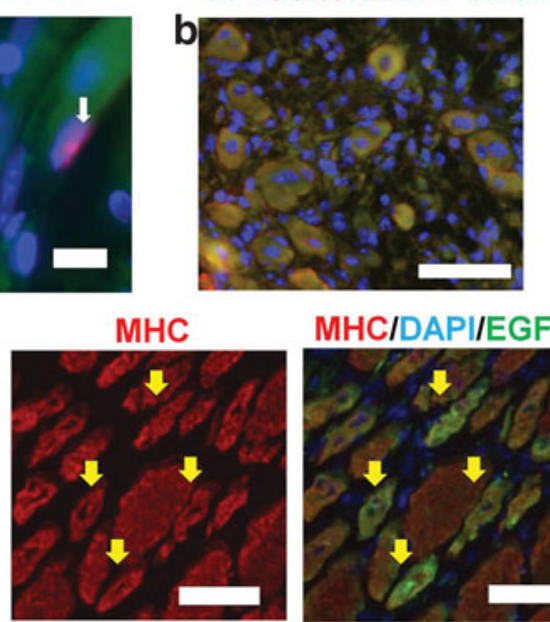

EGFP/Hematoxylin

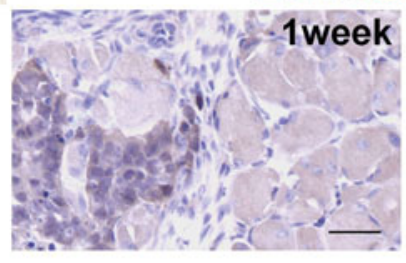

MHC

MHC/DAPI/EGFP
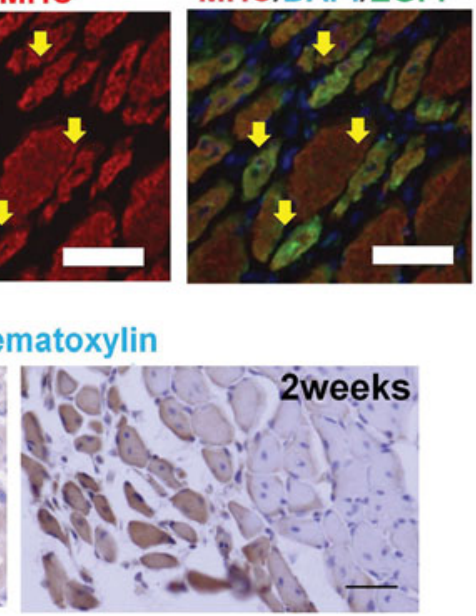

\section{B Ratio of myogenesis}

of E-MSCs in vivo

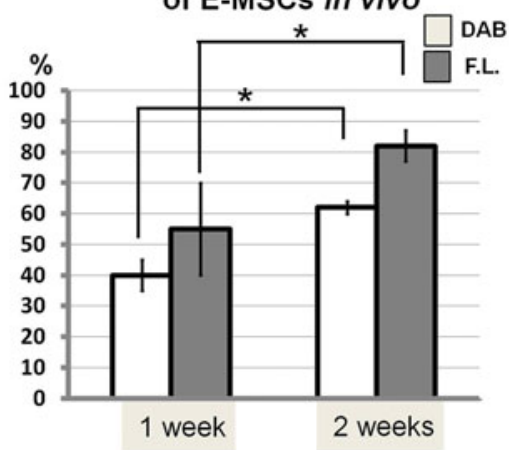

C

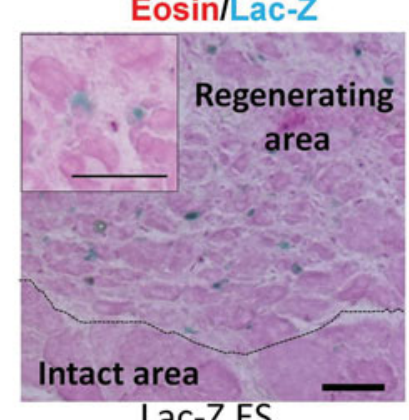

D

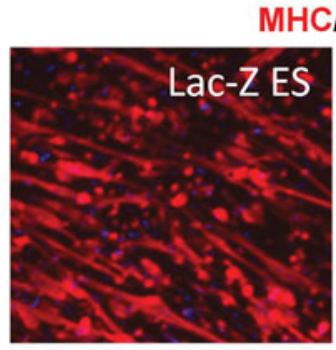

MHCIDAPI

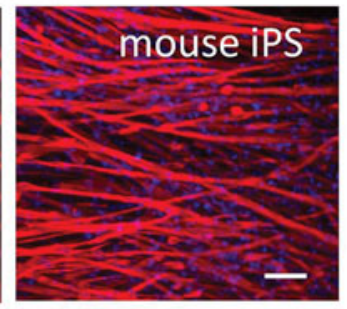

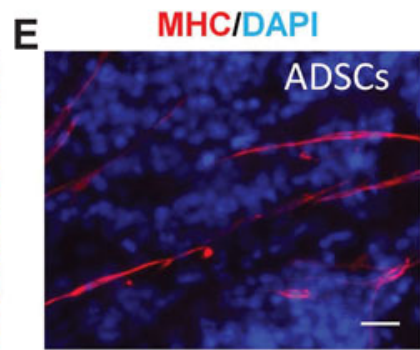

FIG. 3. Confirmation of potential for differentiation into skeletal muscles of MSCs derived from several ES cell and iPS cell lines. (A) Regeneration of injured muscles and myogenesis of transplanted E-MSCs are demonstrated after 1 and 2 weeks of transplantation. (a) A major muscle satellite cell marker, Pax7 (red), was expressed (white arrows) in a nucleus (blue). Pax7positive nucleus indicated by arrow is attached to EGFP-positive muscle cells (green) originating from E-MSCs. Scale bar $=10$ $\mu \mathrm{m}$. (b) M-cadherin (red), a marker of myoblasts, was co-localized with EGFP + cells (green) derived from E-MSCs. Scale bar= $50 \mu \mathrm{m}$. (c) After transplantation, EGFP + cells were identified among injured muscles of SCID mice. Yellow arrows indicate transplanted cells that express EGFP. Regenerating muscle fibers with nuclei located at the center of the cells and occasionally appearing as multinuclear cells in the cross section showed MHC immunoreactivity. Yellow arrows indicate $\mathrm{MHC}^{+}$cells (shown in green). Some EGFP ${ }^{+}$cells expressed MHC immunoreactivity. Scale bar $=50 \mu \mathrm{m}$. (d) $\mathrm{EGFP}^{+}$cells indicating transplanted cells were revealed by horseradish peroxidase (HRP) histochemistry and turned brown, and nuclei were stained by hematoxylin at 1 week and 2 weeks after transplantation. Scale bar $=50 \mu \mathrm{m}$. (B) High ratio of myogenesis among transplanted E-MSCs. The sum of all EGFP ${ }^{+}$cells in the transplanted area was taken as $100 \%$ and the percentages of EGFP and MHC double-positive muscle fibers were calculated at 1 week and 2 weeks after transplantation (gray bars indicated as calculation by fluorescent staining [F.L.]). At 2 weeks post-transplantation, EGFP and MHC double-positive skeletal muscles increased significantly. $\mathrm{EGFP}^{+}$muscle fibers were also calculated by HRP immunohistochemistry (white bars indicated as 3,3'-diaminobenzidine $[\mathrm{DAB}]$ ) and in the serial section stained with eosin. High ratio of myogenesis from transplanted E-MSCs is shown. ${ }^{*} p<0.05$. (C) Histology of the regenerative process 1 week after transplantation. MSCs derived from Lac-Z ES cells were stained with X-gal staining (nuclei in blue). Myofibers were stained with eosin. Transplanted cells expressing X-gal were detected at the regenerating area of the transplanted muscle, but not at the intact area. Inset: Higher magnification shows muscle fibers derived from Lac-Z ES cells including nuclei stained with X-gal (blue). Scale bar $=50 \mu \mathrm{m}$. (D) MHC was expressed with high efficiency in the skeletal muscle fibers derived from Lac-Z ES cells (left) and mouse iPS cells (right). Scale bar $=50 \mu \mathrm{m}$. (E) Potentials for differentiation into skeletal muscles of ADSCs in vitro was limited. We incubated MSCs from adipose tissue (regular MSCs; ADSCs) under the same conditions that induced myogenesis with high potential in E-MSCs $(\sim 40 \%){ }_{1}^{13}$ but ADSCs showed very low myogenic potential $(\sim 2 \%)$. Scale bars $=50 \mu \mathrm{m}$. 

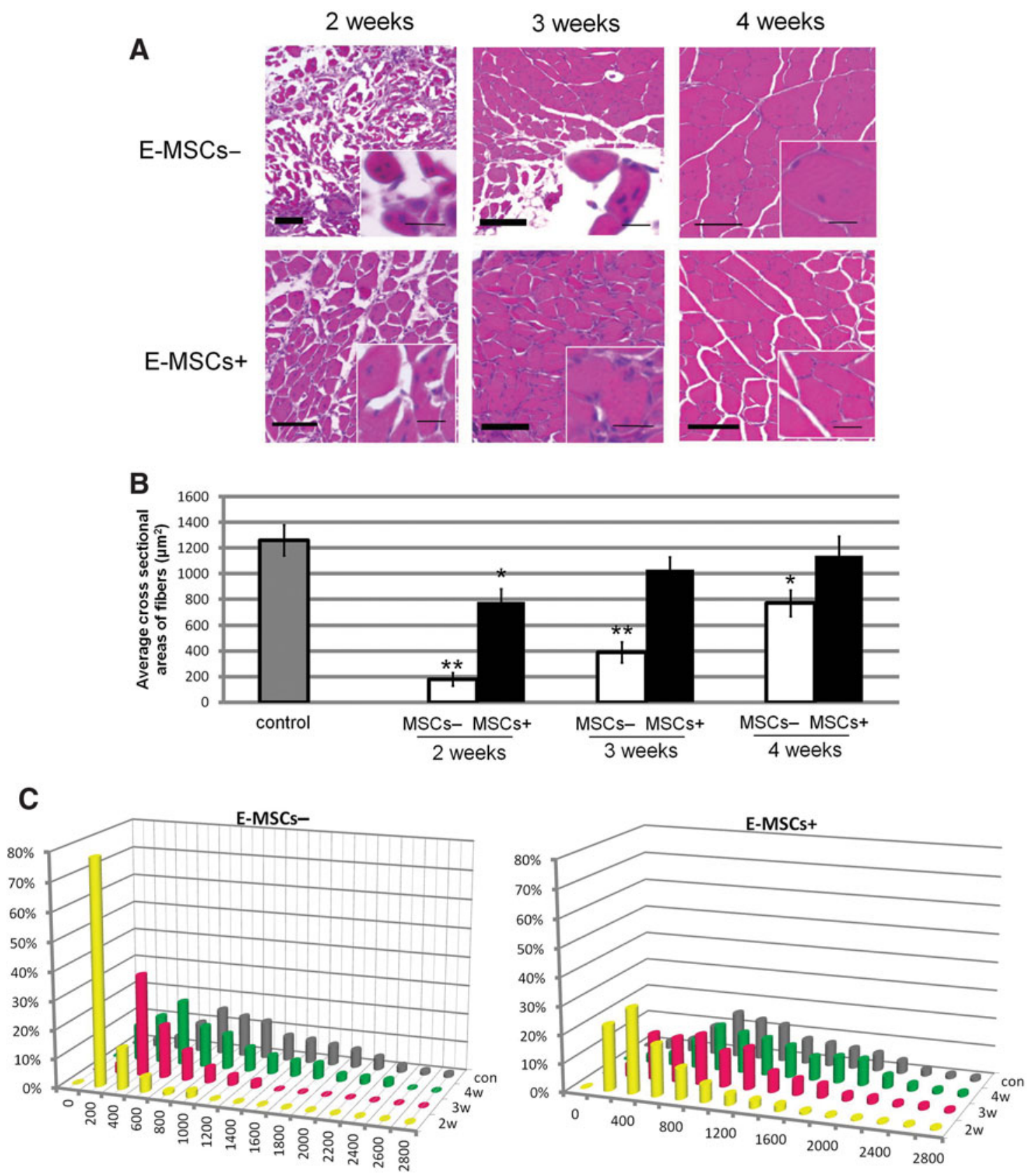

FIG. 4. Acceleration of recovery by transplanted E-MSCs. (A) Histology of the recovery process 2, 3, and 4 weeks after transplantation $\left(\mathrm{E}-\mathrm{MHCs}^{+}\right.$, bottom) were colored with $\mathrm{H}-\mathrm{E}$ staining and the cross-sectional area was compared to that of animals without transplantation (E-MHC ${ }^{-}$, top). The newly formed muscle fibers were stained with eosin (red), gradually expanded in cross-sectional area, and became mature muscle fibers in turn. Insets: Higher magnifications, representing injured muscle histology and regeneration by position of nuclei stained with hematoxylin (blue) in muscle fibers. The centronucleated fiber is a hallmark of muscle regeneration, indicating newly formed muscle fibers. In mature muscle fibers, the nucleus exists in a marginal part. Scale bars $=20 \mu \mathrm{m}$ for insets; $100 \mu \mathrm{m}$ for main image. (B) Average cross-sectional areas of MSC ${ }^{+}$and MSC $^{-}$ injured TA muscle fibers $\left({ }^{*} p<0.05 ;{ }^{* *} p<0.01\right)$. $\mathrm{MSC}^{+}$muscles had increased cross-sectional areas earlier than MSC ${ }^{-}$muscles. (C) Frequency histograms showing the distribution of cross-sectional areas of myofibers in muscles of control animals that were injured but not E-MSC-transplanted (gray bar), injured muscles after E-MSC transplantation (yellow bar), injured muscles 3 weeks after transplantation (red bar), and injured muscles 4 weeks after transplantation (green bars), respectively. Percentile histograms of cross-sectional area of TA muscle fibers in $\mathrm{MSC}^{+}$and $\mathrm{MSC}^{-}$muscles are compared in these graphs. Twenty random sections in three animals in both groups were measured. 
A
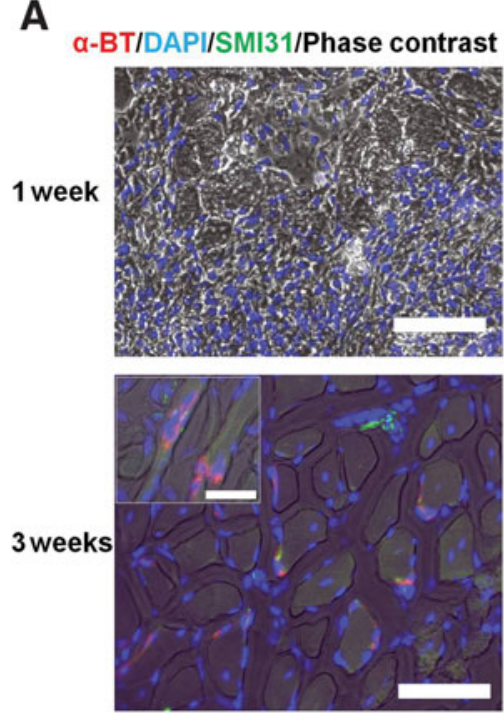
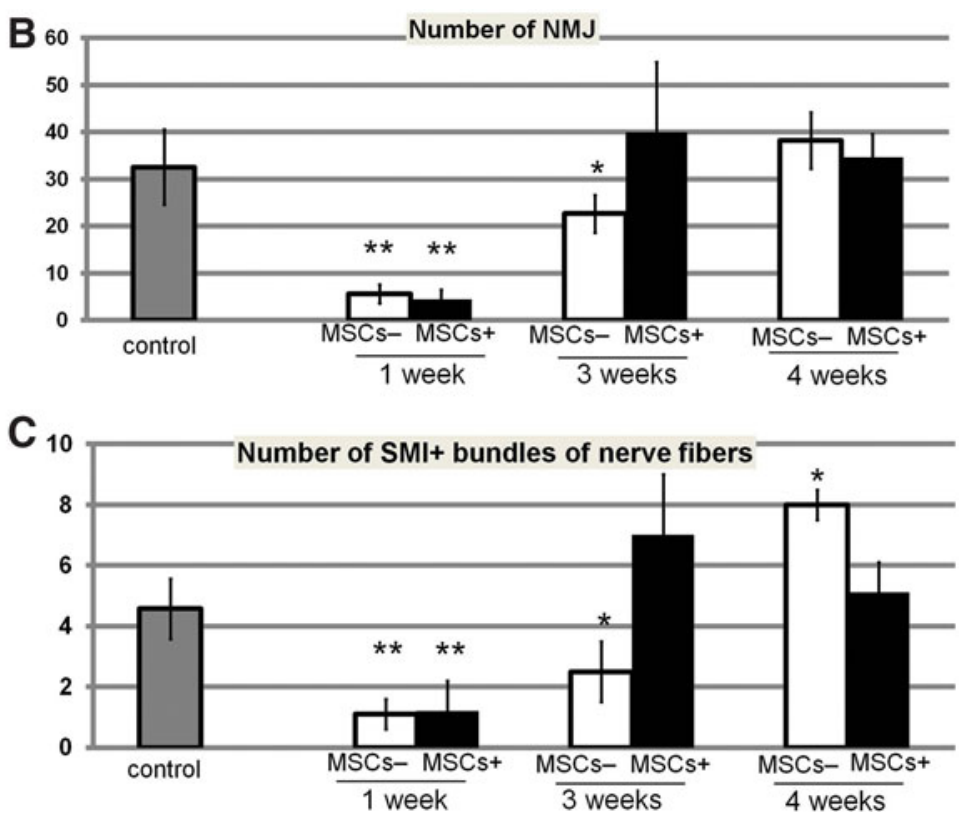

FIG. 5. Earlier regeneration of neuromuscular junctions (NMJs) by transplantation of E-MSCs. (A) NMJs in regenerating TA muscle with transplantation of MSCs are demonstrated by Alexa Fluor 594-conjugated $\alpha$-bungarotoxin $(\alpha-\mathrm{BT})$ and indicated in red. Neurofilaments stained with SMI-31 are in green and nuclei are in blue with DAPI. Although $\alpha$-BT and SMI-31 immunoreactivity almost disappeared 1 week after transplantation, NMJs indicated by $\alpha$-BT and SMI-31 immunoreactivities were clearly recognized after 3 weeks. Scale bars $=50 \mu \mathrm{m}, 10 \mu \mathrm{m}$ for insets. (B) NMJs per each cross section of injured MSC ${ }^{+}$and $^{-}$ MSC $^{-}$TA muscles. Twenty random sections in three animals in both groups were measured $\left({ }^{*} p<0.05,{ }^{* *} p<0.01\right)$. (C) SMI$31^{+}$bundles of nerve fibers in each cross section of injured $\mathrm{MSC}^{+}$and $\mathrm{MSC}^{-} \mathrm{TA}$ muscles. Twenty random sections in three animals in both groups were measured $\left({ }^{*} p<0.05,{ }^{* *} p<0.01\right)$.

\section{Functional recovery of injured muscles with or without transplantation of E-MSCs}

Motor functions of injured TA muscles were analyzed by CatWalk XT once a week after injury. Footsteps of all hind legs were measured and quantified, after which the functional performances of MSC-transplanted $\left(\mathrm{E}^{\left.-\mathrm{MSC}^{+}\right)}\right.$and sham-operated (E-MSC ${ }^{-}$) animals were compared (Fig. 6A). The percentile of the load response phase was calculated and evaluated as a functional recovery of the TA muscles shown in Figure 6B. Until the second and third weeks, the recovery levels of functional performance were also compared between an animal's injured right hind leg and noninjured left hind leg, and we obtained the same results (data not shown). Two weeks after injury, E-MSC ${ }^{+}$mice showed a significant increase in the percentile of the load-response phase, thus indicating functional improvement; after 3 weeks it reached the normal level, while E-MSC ${ }^{-}$animals began to recover (Fig. 6C).

A maximum contact area also indicates functional recovery. One week after injury, both groups showed a reduction of the maximum contact area because of pain escape behavior. Usually freedom from pain recovers the maximum contact area up to the control level; however, injured TA muscles also increased the maximum contact area. Therefore, severe injury increased it beyond the control level. After 1 week, $\mathrm{E}-\mathrm{MSC}^{+}$animals began to increase their maximum contact area, reaching almost the control level after 3 weeks, while the sham group (E-MSC ${ }^{-}$) showed a significant increase in the maximum contact area beyond the control level. This abnormal expansion of a maximum contact area indicates a delay in the functional recovery of a TA muscle of $\mathrm{E}-\mathrm{MSC}^{-}$mice (Fig. 6D). E-MSC ${ }^{-}$mice required more than 4 weeks to attain functional recovery.

\section{Discussion}

\section{Transplantation of E-MSCS}

In our models, since skeletal muscles were crushed by forceps under the same pressure and during the same time period, trauma among the animals was almost identical and reproducible. A TA muscle injury does not severely handicap an animal. However, physical damage to TA muscles can be detected and analyzed clearly by CatWalk XT when they are wounded.

In injured mice, the whole area of the TA muscle crushed by forceps suffered intensive damage and rapidly degenerated, and inflammation peaked $24-48 \mathrm{~h}$ after injury. Then the regeneration of the muscle occurred and could be recognized morphologically 1 week after injury (Fig. 2A). When E-MSCs were transplanted into noninjured muscles, they remained in an undifferentiated state, neither proliferating nor differentiating into mesenchymal cells, such as muscles and/or blood vessels (data not shown). These findings strongly suggest that the differentiation of E-MSCs requires the inflammation or degeneration of the skeletal muscles. Kuraitis et al. ${ }^{16}$ and Joe et al. ${ }^{17}$ determined that the myogenesis of MSCs in vivo required an extracellular matrix such as collagen and severely stressed conditions like an injury. Indeed, E-MSCs transplanted $24 \mathrm{~h}$ after injury showed the highest potential for muscle fiber differentiation from 

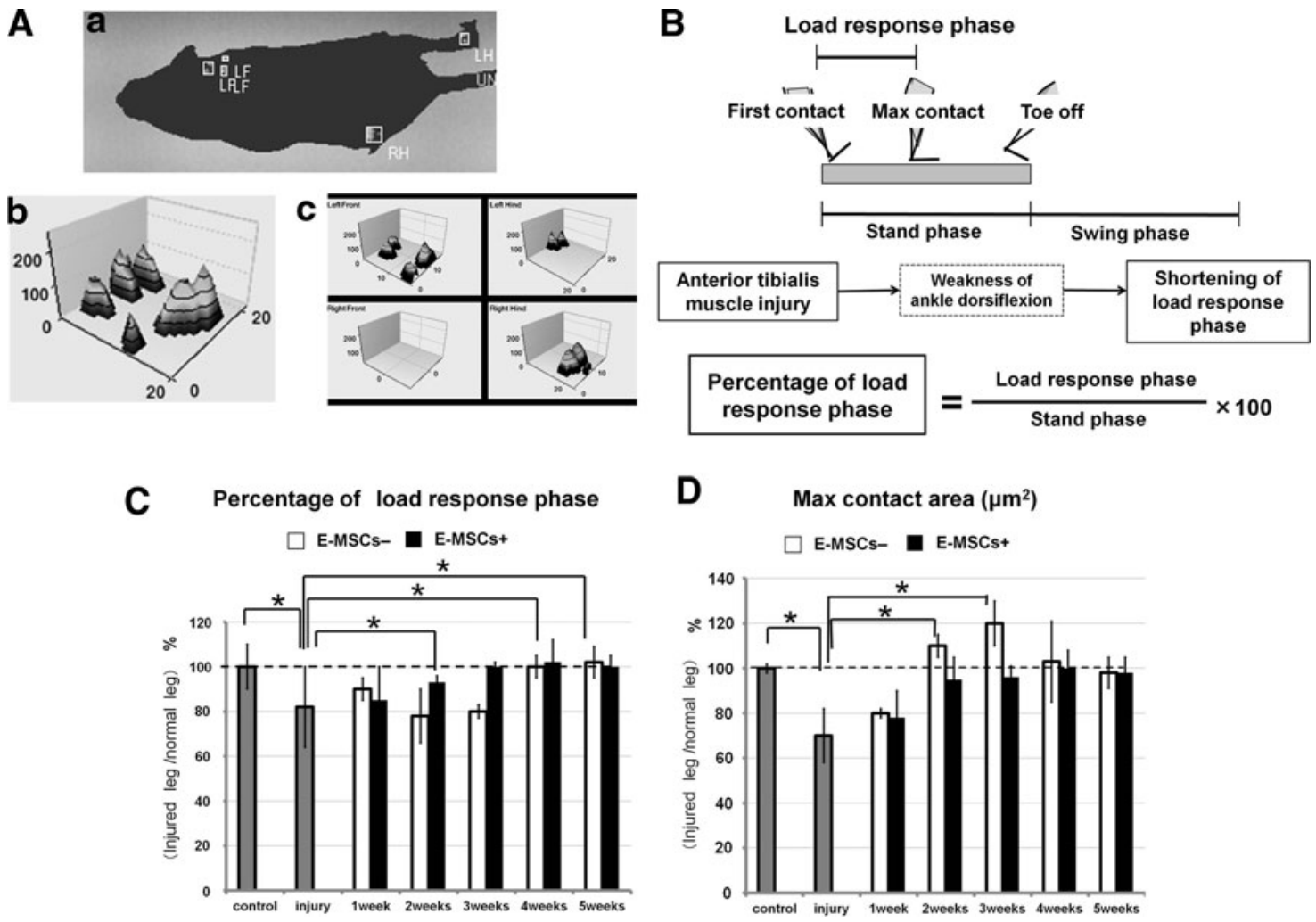

FIG. 6. Functional recovery of injured muscles with or without transplantation of E-MSCs. (A) Animals were placed at one end of a runway ( $150 \mathrm{~cm}$ long, $20 \mathrm{~cm}$ wide, with opaque walls $20 \mathrm{~cm}$ in height), and usually crossed the distance spontaneously. Video recording was conducted from below through a transparent glass floor (see Supplementary Video). Using frame-byframe playback, the individual footprints (a) and a number of "single-paw" (b, c) and interlimb coordination parameters were obtained as follows: 1. Stance Phase Duration, time of paw contact with the glass floor; 2. Load Response Phase Duration, time of first heel contact with maximum foot contact; and 3. Maximum Contact Area, total surface area of the glass floor contacted by the paw during the complete stance phase, which would decrease if the animal was attempting to avoid placing a certain part of the plantar hind paw on the floor. (B) Measurement of functional recovery of injured skeletal muscles. A step cycle is made up of two phases: the swing phase, and stand phase that involves a load-response phase. The percentage of the load-response phase was used for the evaluation index of functional recovery of injured TA muscles. (C) Percentage of loadresponse phase. Two weeks after injury, animals with transplantation (MSC ${ }^{+}$) significantly increased the percentage of the load-response phase, and their legs began to recover functionally. After 3 weeks, the percentage of the load-response phase almost reached a normal level. Meanwhile, legs of sham animals ( $\mathrm{MSC}^{-}$) began to recover at 3 weeks and the response phase reached the normal level at 4 weeks. Broken lines indicate normal levels $\left({ }^{*} p<0.05\right)$. (D) Maximum contact area. One week after injury, both groups $\left(\mathrm{MSC}^{+}, \mathrm{MSC}^{-}\right.$) showed reduction of maximum contact area because of the escape behavior from lameness. After 2 weeks, sham-operated animals ( $\mathrm{MSC}^{-}$) showed excess abnormal contact area. Animals with transplantation $\left(\mathrm{MSC}^{+}\right)$did not exhibit such abnormal expansion of maximum contact area, although the sham group (MSC ${ }^{-}$) still showed it at 4 weeks. After 5 weeks, the sham group $\left(\mathrm{MSC}^{-}\right)$showed the normal level $\left({ }^{*} p<0.05\right)$.

E-MSCs in the present study as shown in the literature. Therefore, we performed transplantation $24 \mathrm{~h}$ after an injury at the peak of the inflammation and degeneration before the onset of muscle regeneration.

\section{E-MSCs potential for differentiation into skeletal muscles to facilitate recovery of injured muscles}

Many investigations have exploited the potential of cell transplantation therapies for the promotion of muscle regeneration. Various cell types isolated from adult tissues including progenitor cells of skeletal muscles, mesoangioblasts obtained from vessels and MSCs from various tissues such as adipose tissue and bone marrow have exhibited their potential for muscle regeneration. ${ }^{10,18-31}$ Although such adult stem cells are involved in the regeneration of host skeletal muscle tissue, their functional contributions to muscle regeneration have not yet been clearly demonstrated. In general, since MSCs from adult tissue exhibit poor potential for differentiation into skeletal muscle cells in vitro, more than $(1-5) \times 10^{6}$ cells are required for cellular transplantation therapy. Recently, several investigators reported that ES cellbased myogenic progenitor cells were useful when they were transplanted into a dystrophy animal. ${ }^{4,6,15,32}$ Such cells differentiate into skeletal muscle cells and generate dystrophin, thus improving the physical condition of an animal. In the present study, we demonstrate that E-MSCs show an extremely high potential for differentiation into skeletal muscles in vivo and promote histological and functional recovery. Only $1 \times 10^{5}$ cells were sufficient to transplant in the present system. Therefore, E-MSCs might have a therapeutic efficiency not only for crush injury but also for Duchenne 
muscular dystrophy. The prominent potential of our MSCs from E-MSCs to differentiate into skeletal muscle probably depends on the medium containing insulin and triiodothyronine for adipogenesis before sorted by MACS. ${ }^{13}$ Moreover, a current report indicated that ES cells treated with RA and insulin increased their myogenic potentials. ${ }^{33-35}$

Furthermore, we confirm the potential to differentiate into skeletal muscle of two more distinct ES cell lines and one iPS cell line to indicate reproducibility (Fig. 3D). All of them show the high potential for myogenesis in vitro and in vivo as well as G4-2 ES cells. Because of their avoidance of the alloimmune response, iPS cells have a great advantage for the transplantation clinic. MSCs from iPS cells would be the most useful for regeneration muscle therapy.

Our results clearly show that 1 week after transplantation, when regeneration of the skeletal muscle began, EGFP-labeled E-MSCs expressed M-cadherin, indicating newly formed immature myofibers with centrally located nuclei. EGFP-labeled cells also accompanied Pax7-positive satellite cells, though we could not demonstrate whether or not these satellite cells originated from E-MSCs. Myofibers from E-MSCs proved conductive to the growth of new or hybrid muscle fibers between host cells and E-MSCs through cell fusion. Furthermore, 2 weeks after transplantation, myofibers expressing both EGFP and MHC exhibited mature characteristics with peripheral nuclei just beneath the plasma membrane, but their cross-sectional areas were even smaller than those of noninjured muscle fibers. After 3 weeks, they grew into cross-sectional areas as extensive as those of noninjured muscle fibers. During the same period, nontransplanted injured TA muscle still showed a lower value for a crosssectional area. It is difficult to explain such a quick recovery of the sectional area in transplanted mice given our small number of E-MSCs, even though $80 \%$ of the transplanted E-MSCs $\left(\mathrm{EGFP}^{+}\right.$cells) expressed MHC and differentiated into muscle cells (Fig. 3B). We reported in a previous study that our E-MSCs differentiated into blood vessels in vivo and also induced the angiogenesis of host blood vessels. ${ }^{13}$ Therefore, some transplanted E-MSCs in that experiment differentiated into blood vessels and probably generated growth factors inducing angiogenesis, such as vascular endothelial growth factor (VEGF), which promotes both muscle cell regeneration and growth. ${ }^{36,37}$ Thus, we speculate that accelerated skeletal muscle regeneration is partly due to the paracrine activity of E-MSCs, and that the angiogenesis induced by E-MSCs may contribute to the regeneration of injured muscles. Such speculation requires further investigation.

\section{Acceleration of re-innervation by E-MSCs}

Our results have demonstrated that peripheral nerve bundles and NMJs disappear from the injured area in cross sections, and they are recovered only gradually. Three weeks after injury, fluorescent $\alpha$-BT indicating NMJs in an injured area rapidly increased in E-MSC transplanted TA muscles $\left(\mathrm{E}_{-} \mathrm{MSC}^{+}\right)$. The numbers of NMJs and regenerating nerve fibers in the TA muscles of ${\mathrm{E}-\mathrm{MSC}^{+}}^{+}$mice were more than those in injured TA muscles not transplanted $\left(\mathrm{E}-\mathrm{MSC}^{-}\right)$at the corresponding time point. Transplanted E-MSCs clearly accelerated re-innervation in TA muscles. In previous work on tibial nerve crush injury, hyper-innervations of NMJs were observed after injury and reverted back to the normal level at the same time as the functional recovery. ${ }^{38}$ Our results of hyper-innervation at 3 weeks are consistent with previous reports. Gordon et al. ${ }^{39}$ reported that delayed peripheral nerve repair caused a diminution in functional recovery. Thus, the promotion of peripheral nerve regeneration shown in this study is one of the mechanisms leading to the functional recovery of injured muscles.

MSCs have been reported to secrete a wide array of cytokines, such as basic fibroblast growth factor (b-FGF), VEGF, monocyte chemoattractant protein-1, and stem cell-derived factor-1, all of which are well-known factors indicative of neuro-supportive effects. ${ }^{40-43}$ Regenerating muscles also produce nerve growth factors such as nerve growth factor (NGF) and glial cell line-derived neurotrophic factor (GDNF). ${ }^{44-47}$ Our findings and those of previous descriptions strongly suggest that E-MSCs themselves and their derivatives (regenerating skeletal muscles) have the potential to produce and secrete growth factors, cytokines, and/or nutrients to the surrounding tissue so as to promote their recovery from tissue damage.

\section{Early functional recovery of injured muscles with transplantation of E-MSCS}

Although many investigations based on histological analysis have reported that progenitor/stem cells transplanted into skeletal muscle have the potential for differentiation into skeletal muscle, only a few have described any improvements in functional recovery. ${ }^{48}$ Gang et al. ${ }^{49}$ measured the muscle electro-physiological activity of mdx mice and indicated that an engraftment of MSCs derived from bone marrow was not accompanied by a functional recovery. Their MSCs showed lower differentiation potential into skeletal muscle in vitro than that of our E-MSCs. They also reported that the ratio of donor-derived myofibers in engrafted muscles varied by $11 \%$, which was lower than that of our E-MSCs, which scored more than $60 \%$. They showed that the cross-sectional area of skeletal muscles in transplanted MSCs did not increase compared with those in injured TA muscles without transplantation at the corresponding time point. Our data using ADSCs confirms the poor differentiation potential into skeletal muscle cells, even if they are cultured in the same myogenic media as E-MSCs that probably promote myogenic differentiation of E-MSCs (Fig. 3E). On the other hand, Darabi et al. ${ }^{7,32}$ and Ryan et al. ${ }^{33}$ reported on the functional skeletal muscle regeneration from differentiating Pax3induced ES cells and Pax7-induced iPS cells. They assessed the locomotive recovery of injured mdx mice and improved their performance on the rotarod. In agreement with the result of a functional assessment, the cross-sectional area of transplanted mice was more extensive than that of nontransplanted muscles. Our results are consistent with that description and show higher efficacy.

In the present study, functional recovery was analyzed precisely by a CatWalk using two independent parameters. Percentiles of the load-response phase clearly recovered to the control level after 3 weeks in the animals with E-MSCs transplantation, which was 1 week earlier than that in the animals without transplantation. The maximum contact area also demonstrated an earlier recovery in the mice with cellular transplantation. We show for the first time that the transplantation of E-MSCs promotes a functional recovery of TA 
muscles injured mechanically. Such functional recoveries are consistent with the results of histological data described above.

In conclusion, E-MSCs exhibit a high potential for differentiation into skeletal muscles in vivo as well as in vitro. The transplantation of E-MSCs promotes a functional recovery of injured muscles by an acceleration of muscle regeneration and a re-innervation of the peripheral nerves. Thus, cell therapy using MSCs derived from pluripotent stem cells (i.e., ES cells and iPS cells) is one of the effective and safe ways to improve functional recovery of damaged skeletal muscles.

\section{Acknowledgments}

We wish to thank Dr. H. Niwa (Riken, Kobe, Japan), Dr. H. Sakurai (Kyoto University, Kyoto, Japan), and Dr. K. Sasaki and Mr. S. Yoshie (Shinshu University, Nagano, Japan) for their generous gifts of mouse ES cells; Mr. K. Kohdo (Brain Science Idea Co., Ltd.) for his technical support of CatWalk; and Dr. K. Watanabe (Leica Japan) for his skillful expertise in laser irradiation using laser microdissection. This work was supported by Grants-in-Aid for Scientific Research Japan (S), (B), and for Challenging Exploratory Research.

\section{References}

1. Cossu G, Mavilio F. Myogenic stem cells for the therapy of primary myopathies: wishful thinking or therapeutic perspective? J Clin Invest. 2000;105:1669-1674.

2. Hardy K, Carthew P, Handyside AH, et al. Extragonadal teratocarcinoma derived from embryonal stem cells in chimaeric mice. J Pathol. 1990;160:71-76.

3. Barberi T, Bradbury M, Dincer Z, et al. Derivation of engraftable skeletal myoblasts from human embryonic stem cells. Nat Med. 2007;13:642-648.

4. Sakurai H, Okawa Y, Inami Y, et al. Paraxial mesodermal progenitors derived from mouse embryonic stem cells contribute to muscle regeneration via differentiation into muscle satellite cells. Stem Cells. 2008;26:1865-1873.

5. Mizuno Y, Chang H, Umeda K, et al. Generation of skeletal muscle stem/progenitor cells from murine induced pluripotent stem cells. FASEB J. 2010;24:2245-2253.

6. Bhagavati S, Xu W. Generation of skeletal muscle from transplanted embryonic stem cells in dystrophic mice. Biochem Biophys Res Commun. 2005;333:644-649.

7. Darabi R, Pan W, Bosnakovski D, et al. Functional myogenic engraftment from mouse iPS cells. Stem Cell Rev. 2011;7:948957.

8. Locke M, Feisst V, Dunbar PR. Concise review: human adipose-derived stem cells: separating promise from clinical need. Stem Cells. 2011;29:404-411.

9. de la Garza-Rodea AS, van der Velde-van Dijke I, Boersma $\mathrm{H}$, et al. Myogenic properties of human mesenchymal stem cells derived from three different sources. Cell Transplant. 2012;21:153-173.

10. De Bari C, Dell'Accio F, Vandenabeele F, et al. Skeletal muscle repair by adult human mesenchymal stem cells from synovial membrane. J Cell Biol. 2003;160:909-918.

11. Dezawa M, Ishikawa $H$, Itokazu $Y$, et al. Bone marrow stromal cells generate muscle cells and repair muscle degeneration. Science. 2005;309:314-317.

12. Liu $Y$, Yan X, Sun Z, et al. Flk-1 + adipose-derived mesenchymal stem cells differentiate into skeletal muscle satellite cells and ameliorate muscular dystrophy in mdx mice. Stem Cells Dev. 2007;16:695-706.

13. Ninagawa N, Murakami R, Isobe E, et al. Mesenchymal stem cells originating from ES cells show high telomerase activity and therapeutic benefits. Differentiation. 2011;82:153-164.

14. Okita K, Nakagawa M, Hyenjong H, et al. Generation of mouse induced pluripotent stem cells without viral vectors. Science. 2008;322:949-953.

15. Darabi R, Santos FN, Filareto A, et al. Assessment of the myogenic stem cell compartment following transplantation of Pax3/Pax7-induced embryonic stem cell-derived progenitors. Stem Cells. 2011;29:777-790.

16. Kuraitis D, Giordano C, Ruel M, et al. Exploiting extracellular matrix-stem cell interactions: a review of natural materials for therapeutic muscle regeneration. Biomaterials. 2012;33: 428-443.

17. Joe AW, Yi L, Natarajan A, et al. Muscle injury activates resident fibro/adipogenic progenitors that facilitate myogenesis. Nat Cell Biol. 2010;12:153-163.

18. Asakura A, Seale P, Girgis-Gabardo A, et al. Myogenic specification of side population cells in skeletal muscle. J Cell Biol. 2002;159:123-134.

19. Lee JY, Qu-Petersen Z, Cao B, et al. Clonal isolation of muscle-derived cells capable of enhancing muscle regeneration and bone healing. J Cell Biol. 2000;150:1085-1100.

20. Morosetti R, Gidaro T, Broccolini A, et al. Mesoangioblasts from facioscapulohumeral muscular dystrophy display in vivo a variable myogenic ability predictable by their in vitro behavior. Cell Transplant. 2011;20:1299-1313.

21. Goudenege S, Pisani DF, Wdziekonski B, et al. Enhancement of myogenic and muscle repair capacities of human adiposederived stem cells with forced expression of MyoD. Mol Ther. 2009;17:1064-1072.

22. Di Rocco G, Iachininoto MG, Tritarelli A, et al. Myogenic potential of adipose-tissue-derived cells. J Cell Sci. 2006;119(Pt 14):2945-2952.

23. Sampaolesi M, Torrente Y, Innocenzi A, et al. Cell therapy of alpha-sarcoglycan null dystrophic mice through intraarterial delivery of mesoangioblasts. Science. 2003;301: 487-492.

24. Sampaolesi M, Blot S, D'Antona G, et al. Mesoangioblast stem cells ameliorate muscle function in dystrophic dogs. Nature. 2006;444:574-579.

25. Fakhfakh R, Lamarre Y, Skuk D, et al. Losartan enhances the success of myoblast transplantation. Cell Transplant. 2012;21:139-152.

26. Feng SW, Lu XL, Liu ZS, et al. Dynamic distribution of bone marrow-derived mesenchymal stromal cells and change of pathology after infusing into $\mathrm{mdx}$ mice. Cytotherapy. 2008;10:254-264.

27. Tamaki T, Okada Y, Uchiyama Y, et al. Skeletal musclederived CD34 + /45- and CD34-/45- stem cells are situated hierarchically upstream of Pax + cells. Stem Cells Dev. 2008;17:653-667.

28. Merritt EK, Cannon MV, Hammers DW, et al. Repair of traumatic skeletal muscle injury with bone-marrow-derived mesenchymal stem cells seeded on extracellular matrix. Tissue Eng Part A. 2010;16:2871-2881.

29. Matziolis G, Winkler T, Schaser K, et al. Autologous bone marrow-derived cells enhance muscle strength following skeletal muscle crush injury in rats. Tissue Eng. 2006;12: 361-367.

30. Mori R, Kamei N, Okawa S, et al. Promotion of skeletal muscle repair in a rat skeletal muscle injury model by local 
injection of human adipose tissue-derived regenerative cells. J Tissue Eng Regen Med 2012.

31. Winkler $\mathrm{T}$, von Roth $\mathrm{P}$, Radojewski $\mathrm{P}$, et al. Immediate and delayed transplantation of mesenchymal stem cells improve muscle force after skeletal muscle injury in rats. J Tissue Eng Regen Med 2012.

32. Darabi R, Gehlbach K, Bachoo RM, et al. Functional skeletal muscle regeneration from differentiating embryonic stem cells. Nat Med. 2008;14:134-143.

33. Ryan T, Liu J, Chu A, et al. Retinoic acid enhances skeletal myogenesis in human embryonic stem cells by expanding the premyogenic progenitor population. Stem Cell Rev. 2012;8:482-493.

34. Kennedy KA, Porter T, Mehta V, et al. Retinoic acid enhances skeletal muscle progenitor formation and bypasses inhibition by bone morphogenetic protein 4 but not dominant negative beta-catenin. BMC Biol. 2009;7:67.

35. Bouchard F, Paquin J. Skeletal and cardiac myogenesis accompany adipogenesis in P19 embryonal stem cells. Stem Cells Dev. 2009;18:1023-1032.

36. Kim MH, Hong HN, Hong JP, et al. The effect of VEGF on the myogenic differentiation of adipose tissue derived stem cells within thermosensitive hydrogel matrices. Biomaterials. 2010;31:1213-1218.

37. Cobellis G, Maione C, Botti C, et al. Beneficial effects of VEGF secreted from stromal cells in supporting endothelial cell functions: therapeutic implications for critical limb ischemia. Cell Transplant. 2010;19:1425-1437.

38. Magill CK, Tong A, Kawamura D, et al. Reinnervation of the tibialis anterior following sciatic nerve crush injury: a confocal microscopic study in transgenic mice. Exp Neurol. 2007;207:64-74.

39. Gordon T, Tyreman N, Raji MA. The basis for diminished functional recovery after delayed peripheral nerve repair. J Neurosci. 2011;31:5325-5334.

40. Pan HC, Cheng FC, Chen CJ, et al. Post-injury regeneration in rat sciatic nerve facilitated by neurotrophic factors secreted by amniotic fluid mesenchymal stem cells. J Clin Neurosci. 2007;14:1089-1098.

41. Shibata T, Naruse $K$, Kamiya $H$, et al. Transplantation of bone marrow-derived mesenchymal stem cells improves diabetic polyneuropathy in rats. Diabetes. 2008;57:30993107.

42. Oliveira JT, Almeida FM, Biancalana A, et al. Mesenchymal stem cells in a polycaprolactone conduit enhance mediannerve regeneration, prevent decrease of creatine phosphokinase levels in muscle, and improve functional recovery in mice. Neuroscience. 2010;170:1295-1303.

43. Grumbles RM, Sesodia S, Wood PM, et al. Neurotrophic factors improve motoneuron survival and function of muscle reinnervated by embryonic neurons. J Neuropathol Exp Neurol. 2009;68:736-746.

44. Nagano M, Suzuki H. Quantitative analyses of expression of GDNF and neurotrophins during postnatal development in rat skeletal muscles. Neurosci Res. 2003;45:391-399.

45. Suzuki H, Hase A, Kim BY, et al. Up-regulation of glial cell line-derived neurotrophic factor (GDNF) expression in regenerating muscle fibers in neuromuscular diseases. Neurosci Lett. 1998;257:165-167.

46. Henderson CE, Phillips HS, Pollock RA, et al. GDNF: a potent survival factor for motoneurons present in peripheral nerve and muscle. Science. 1994;266:1062-1064.

47. Vianney JM, Spitsbergen JM. Cholinergic neurons regulate secretion of glial cell line-derived neurotrophic factor by skeletal muscle cells in culture. Brain Res. 2011;1390:1-9.

48. Winkler T, von Roth P, Matziolis G, et al. Dose-response relationship of mesenchymal stem cell transplantation and functional regeneration after severe skeletal muscle injury in rats. Tissue Eng Part A. 2009;15:487-492.

49. Gang EJ, Darabi R, Bosnakovski D, et al. Engraftment of mesenchymal stem cells into dystrophin-deficient mice is not accompanied by functional recovery. Exp Cell Res. 2009;315: 2624-2636.
Address correspondence to: Shigeko Torihashi, PhD 1-1-20 Daikouminami Higashi-ku, Nagoya 461-8673 Japan E-mail: storiha@met.nagoya-u.ac.jp 